\title{
Fine Needle Aspiration Cytology In The Diagnosis Of Head And Neck Masses
}

\author{
Akeel A. Khdhayer \\ /F.I.C.M.S, C.A.B.S (Oral, head and neck surgery) \\ /Sulaimani Teaching Center, ENT department \\ Mazin Jasim Al-Azawi \\ /F.R.C.S/Consultant otolaryngologist \\ Nawal Al-Alash \\ /F.R.C Path \\ Hadeel A. Yasseen \\ / assistant professor (Histopathology) \\ University of Sulaimani/School of Medicine
}

\begin{abstract}
Background Commonly presenting neck masses occur within lymph nodes, thyroid, parotid and other salivary glands. Objective This study is designed to assess the accuracy, sensitivity, specificity in various head and neck lesions Material and method fine needle cytology and the histopathology were done on 100 patients who presented with palpable head and neck mass (es). Result Sensitivity, specificity, and accuracy for detection of lymphoma is $50 \%, 90 \%, 70.0 \%$ respectively. While the overall sensitivity, specificity, accuracy is $88 \%, 98 \%, 93 \%$. Conclusion fine needle aspiration is a highly accurate method for primary diagnosis of neck masses apart from lymphoma.
\end{abstract}

Keywords: Accuracy, cytology, neck masses, Fine needle aspiration

\section{Introduction}

Palpable masses in the head and neck region include a wide range of differential diagnosis, ranging from simple inflammatory masses to more complicated neoplasms, with both benign and malignant entities (Lumley, Chan, Harris \& Zangana,1997). Commonly presenting neck masses occur within lymph nodes, thyroid, parotid and other salivary glands. Less common pathologies presenting as neck swellings are from thyroglossal cysts, branchial cleft cysts, carotid body tumors, cystic hygromas, pharyngeal pouch abnormalities and tumours of skin appendages 
(Rapkiewicz, Le BT, Simsir, Cangiarella \& Levine, 2007). In every circumstance, fine needle aspiration (FNA) is a test that should be interpreted with the entire clinical circumstances. False-negative and false-positive FNA results are reported in almost every series. Therefore, reliance upon FNA findings at the expense of clinical, radiographic, or other findings is unsafe (Salgarelli, Cappare, Bellini\& Collini, 2009). In the head and neck region, FNAC is of great value because of the multiplicity of accessible organs and heterogeneous pathologies encountered. An early differentiation of benign from malignant pathology greatly influences the planned treatment (Watkinson, Wilson, Gaze, Stell\& Maran, 2000). There is no evidence that the tumor spreads through the skin track created by the fine hypodermic needle used in this technique (Russel, William \& Bulstrode , 2004). FNAC can be both diagnostic and therapeutic in cystic swellings (Afridi, Malik \& Wahed,1995). Fine needle aspiration cytology of lymph node has become an integral part of the initial diagnosis and management of patients with lymphadenopathy due to early availability of results, simplicity, and, minimal trauma with less complication (Keith, Harsharan \& Jerald, 2007). It almost offers an accurate diagnosis for reactive lymphoid hyperplasia, infectious disease, granulomatous lymphadenitis, and metastatic malignancy. Thus, it can avoid the need for excisional biopsy in most cases and allow rapid onset of therapy (Howlett et al, 2007).

\section{Aims of the study}

This study is done to evaluate the role of FNAC as diagnostic method in palpable head and neck masses and to assess its sensitivity, specificity and accuracy.

\section{Materials \& Methods}

This study is a prospective, single-institute study in otorhinolaryingology and head and neck surgery Centre/ Iraq, for a period of 10 months from February-December 2001, in which FNAC was done for 107 patients who presented with palpable head and neck mass(es) which had lasted at least two weeks. Prior to FNAC, the patients were examined with recording of their clinical history and significant clinical findings. Relevant investigations were carried out as per requirements. After a brief explanation of the technique, an informed consent of the patient was obtained. FNA was performed for all cases using a 22-gauge needle. No local anaesthesia and no ultrasound guide were used. Smears were stained by Haematoxylin and Eosin stain. Seven cases were excluded from this study because they refused being biopsied. The remaining 100 cases were subjected to tonsillectomy. Cytological findings were compared with hitopathological reports using the 
statistical methods of Galen and Gambino (1975) method for calculating the sensitivity, specificity and accuracy.

\section{Results}

Out of 100 head and neck masses, 65\% were cervical lymph nodes, $16 \%$ were thyroid nodules, $10 \%$ were submandibular and parotid salivary glands and $9 \%$ were miscellaneous lesions as shown in figure 1.

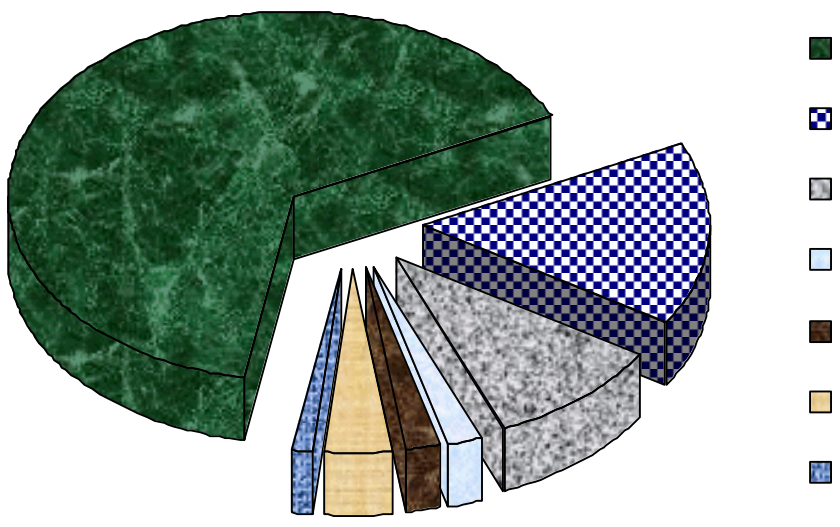

Fig.1 Sites of the aspirated neck masses in 100 cases.

The FNA diagnoses were recorded and compared to the histological diagnoses as shown in table I.

TABLE I Cytological diagnosis compared to histological diagnosis in 100 cases.

\begin{tabular}{|c|c|c|c|c|}
\hline \multirow{2}{*}{ Site of neck mass } & \multicolumn{2}{|c|}{ Cytological diagnosis } & \multicolumn{2}{c|}{ Histological diagnosis } \\
\cline { 2 - 5 } & Benign & Malignant & Benign & Malignant \\
\hline Lymph node & 24 & 41 & 20 & 45 \\
\hline Thyroid gland & 14 & 2 & 13 & 3 \\
\hline Salivary gland & 8 & 2 & 8 & 2 \\
\hline Miscellaneous & 9 & 0 & 9 & 0 \\
\hline Total & 55 & 45 & 50 & 50 \\
\hline
\end{tabular}

By cytological examination of the 65 lymph nodes, 24 patients (36.9\%) were benign and 41 patients $(63.1 \%)$ were malignant of which 6 cases had lymphoma while the remaining 35 cases that constitute the largest group had different metastatic carcinomas, while by histological examination, 20 cases $(30.7 \%)$ had benign lesions and 45 cases $(69.3 \%)$ were malignant of which 35 were metastatic and 10 had lymphoma, as shown in table II which compares the cytological and histological diagnoses of 65 LNs. 
TABLE II Cytological compared to histological diagnosis of the 65 lymph nodes.

\begin{tabular}{|c|c|c|}
\hline No. of cases & Cytological diagnosis & Histological diagnosis \\
\hline 15 & Reactive hyperplasia & Reactive hyperplasia \\
\hline 5 & Reactive hyperplasia & Lymphoma \\
\hline 1 & Non specific lymphadenitis & TB Lymphadenitis \\
\hline 3 & TB lymphadenitis & TB lymphadenitis \\
\hline 10 & \multirow{6}{*}{ Metastatic carcinoma } & Laryngeal carcinoma \\
\hline 7 & & Nasopharyngeal carcinoma \\
\hline 2 & & Hypopharyngeal carcinoma \\
\hline 8 & & Oral cavity \\
\hline 2 & & Thyroid \\
\hline 6 & & Breast \\
\hline 5 & Lymphoma & Lymphoma \\
\hline 1 & Lymphoma & TB lymphadenitis \\
\hline 65 & & \\
\hline
\end{tabular}

Sensitivity for detection of lymphoma is $50.0 \%$, while the specificity is $90.0 \%$ and accuracy is $70.0 \%$.

All 35 cases of metastatic carcinoma were properly diagnosed by cytology with $100 \%$ accuracy, figure 2 shows metastatic poorly differentiated adenocarcinoma to cervical lymph node.
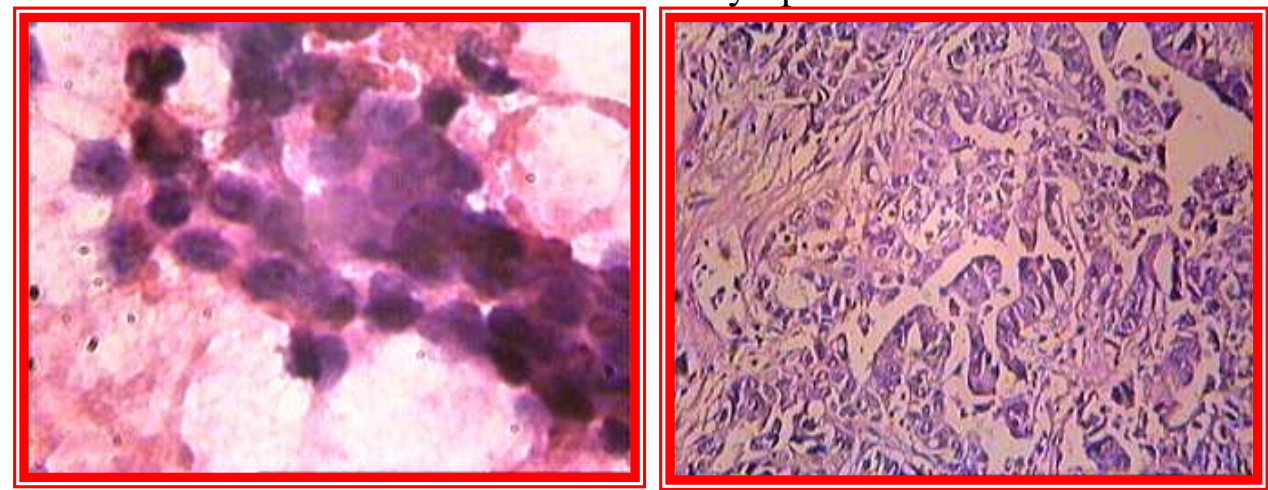

Fig.2 Metastatic poorly differentiated adenocarcinoma to the lymph node, left: cytology H\&E x 400, right: histology H\&E, x100.

The main discrepancy lies in the ten lymphoma cases, 5 cases of lymphoma were misdiagnosed as reactive hyperplasia with accuracy $70.0 \%$ as shown in table III.

TABLE III The comparison between cytological and histopathological diagnosis of 10 lymphoma cases.

\begin{tabular}{|c|c|c|}
\hline No. & Cytological diagnosis & Histological diagnosis \\
\hline 3 & Reactive hyperplasia & Hodgkin's lymphoma \\
\hline 3 & Hodgkin's lymphoma & Hodgkin's lymphoma \\
\hline 2 & Reactive hyperplasia & Non Hodgkin's lymphoma \\
\hline 2 & Non Hodgkin's lymphoma & Non Hodgkin's lymphoma \\
\hline
\end{tabular}


Diagnostic accuracy of Hodgkin's lymphoma is $66.6 \%$, while the diagnostic accuracy of Non-Hodgkin's lymphoma is $75 \%$.

Of the 16 thyroid masses only one case of follicular carcinoma were misdiagnosed as hyperplastic follicular cells. The comparison between cytological and histological diagnosis of thyroid masses was shown in table IV. Figure 3 shows papillary thyroid carcinoma.

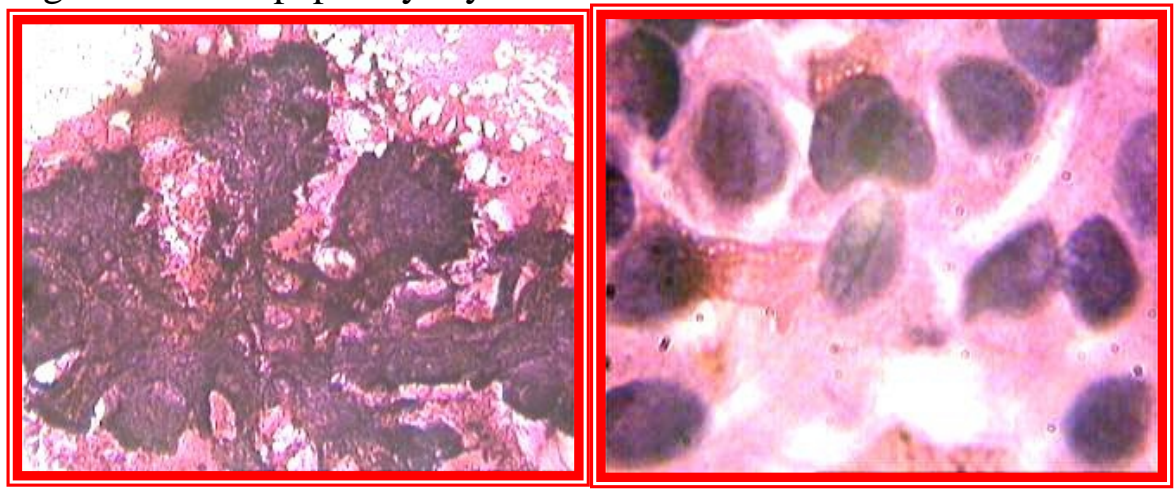

Fig.3 cytology of thyroid papillary carcinoma, H\& E. Right: branched sheet with three dimentional papillary architecture, x100. Left: enlarged overlapping nuclei with intranuclear groove, $\mathrm{x} 1000$.

TABLE IVComparison between cytological and histological diagnosis of 16 thyroid masses.

\begin{tabular}{|c|c|c|}
\hline No. of cases & Cytological diagnosis & Histological diagnosis \\
\hline 13 & Colloid goiter & Nodular colloid goiter \\
\hline 1 & Hyperplastic follicular cells & Follicular carcinoma \\
\hline 1 & Anaplastic carcinoma & Anaplastic carcinoma \\
\hline 1 & Papillary carcinoma & Papillary carcinoma \\
\hline 16 & & \\
\hline
\end{tabular}

Sensitivity for detection of thyroid malignancy is $66.6 \%$ while the specificity is $100 \%$ with $83.3 \%$ accuracy.

From the 10 patients with salivary gland masses, 4 cases were related to parotid and 6 cases were related to submandibular gland. All cases were properly diagnosed by cytological examination apart from one case of Warthin tumour of the parotid was improperly diagnosed as pleomorphic adenoma, shown in table $\mathrm{V}$.

TABLE V The cytological compared to histological diagnosis of the 10 salivary gland masses.

\begin{tabular}{|c|c|c|c|}
\hline Salivary gland & No. & Cytological diagnosis & Histological diagnosis \\
\hline \multirow{3}{*}{ Parotid gland } & 1 & Pleomorphic adenoma & Warthin tumor \\
\cline { 2 - 4 } & 2 & Pleomorphic adenoma & Pleomorphic adenoma \\
\cline { 2 - 4 } & 1 & Mucoepidermoid ca. & Mucoepidermoid ca. \\
\hline Submandibular gland & 5 & Chronic sialadenitis & Chronic sialadenitis \\
\cline { 2 - 4 } & 1 & adenocarcinoma & adenocarcinoma \\
\hline & 10 & & \\
\hline
\end{tabular}


The accuracy $f$ or detection of salivary gland lesion is $90 \%$.

While all 9 cases with miscellaneous masses were properly diagnosed by cytological examination; 2 keratinous cysts of skin, 2 soft tissue lipomas, 2 brancheal cysts, 2 thyroglossal cysts and 1 case of neurofibroma.

The overall sensitivity is $88 \%$, specificity is $98 \%$ and accuracy is $93 \%$ in 100 cases of neck masses as show in figure 4 .

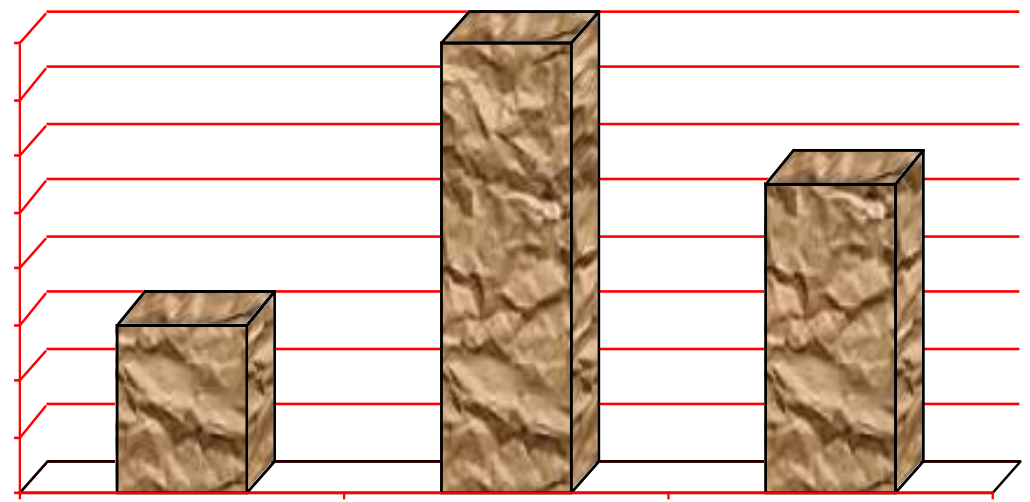

Fig.4 The overall specificity, sensitivity accuracy.

\section{Discussion}

The accuracy of FNA varies with cytopathologist experience and according to the tissues sampled. In this study lymph nodes had undergone excision after FNAC either due to clinical, radiological, or cytological suspicion and the majority (69.3\%) of lymphadenopathy were malignant whether lymphoma or metastatic, while only in 20 cases $(30.7 \%)$ the cervical lymph nodes were benign and they were excised because of negativity of all investigations and no response to medical treatment. This highly correlates with a study done in Egypt by Nasreen and Naveen (2011) in which $69.7 \%$ of their cases had malignant lymphadenopathy. This is also in correlation with Steel, Schwartz and Ibrahim (1995) who found that the majority of their cases were malignant $(59 \%)$.

Tuberculous lymphadenitis may manifest itself as a neck mass. In this study FNA specimens have cytologic evidence consistent with tuberculosis, including granulomatous inflammation and/or caseation necrosis. In Iraq mycobacterial TB infection is common and endemic while other granulomatous conditions as sarcoidosis and fungal lymphadenitis are much less common so diagnosis of tuberculaous lymphadenitis can be made with confidence in smears showing granulomas, giant cells with caseation especially when compatible with clinical manifestations. In this study 3 cases (60\%) were properly diagnosed as TB lymphadenitis while 2 cases were 
misdiagnosed as inflammatory since no granuloma was seen with $95.5 \%$ accuracy. Multiple studies have demonstrated greater than $90 \%$ accuracy in diagnosis of tuberculous lymphadenitis with FNA (Agarwal et al, 2009, Khan et al 2009 \& Maharjan et al 2009).

In the present study, all cases of metastatic carcinoma to the lymph nodes showed exact corroboration with the histopathology. The diagnostic accuracy of these cases was $100 \%$. This finding is comparable to other workers (Hirachand et al 2009, Nesreen et al 2011) who found 100\% accuracy. While others reported $87 \%$ diagnostic accuracy (Khajuria, Goswami, Singh \& Dudey, 2006). In a study of metastatic squamous cell carcinoma of the neck subsequently treated by neck dissection, Knappe, Louw \& Gregor (2000) found that ultrasound-guided FNA had an accuracy of $94 \%$.

In this study 5 out of 10 cases (50\%) of lymphoma of the cervical lymph nodes were misdiagnosed as reactive hyperplasia with $70.0 \%$ accuracy. Three cases of Hodgkin's lymphoma of the lymphocytic predominant type were misdiagnosed as reactive hyperplasia because of absence of Reed Stenberg cell. Others concluded that Hodgkin lymphoma might be missed on cytology as R-S cells and their variant may be relatively sparse or may be masked by preponderance of reactive lymphoid cells (Hehn, Grongan \& Miller,2004). It is fair to say that the diagnosis of nodular lymphocyte predominant Hodgkin lymphoma is extremely challenging to make by FNA (Linda \& Sandhaus,2000).

Meanwhile two cases of low grade non Hodgkin' lymphoma were misdiagnosed as reactive hyperplasia. Al-Alwan, Al-Hashimi, Salman \& AlAttar (1996) concluded that the low-grade non Hodgkin lymphomas with minimal cytomorphological atypia remain very difficult to be evaluated cytologically and they are usually mis-diagnosed as reactive lymphoid hyperplasia.

In the current study, the diagnostic accuracy for Hodgkin lymphoma was $66.6 \%$ which is much lower than Al-Alwan et al (1996) who concluded 76.9\% accuracy rate also Al-Mulhim, Al-Ghamdi, Al-Marzooq, Mohammad \& Gharib (2004) and Das DK (1999) who reported 92\% and 90\% diagnostic accuracy for Hodgkin lymphoma on cytology, respectively.

Diagnostic accuracy of our non Hodgkin lymphoma cases was $75 \%$. This matched with $73.8 \%$ as reported by Landgren, MacDonald, Tani, Ost and Wedelin (2004). Our finding was much lower than that reported by other studies (Keith et al 2007, Al-Mulhim et al 2004, and Al-Alwan et al 1996) who reported $82 \%, 86 \%$, and $88.5 \%$ diagnostic accuracy for non Hodgkin lymphoma cases, respectively. Others concluded lower diagnostic accuracy (67\%) (Dong, Harris, Preffer, Pitman 2001). 
The diagnostic accuracy of the thyroid malignancy in this study is $83.3 \%$, we believe that the accuracy of diagnosis by FNA is dependent on the type and diameter of the lesion being sampled and the experience of those doing the sampling and evaluating the smears. If suspicious cells are detected, surgical excision of the nodule should be the treatment of choice to exclude malignancy.

In our study the diagnostic accuracy is $90 \%$ of preoperative FNA cytology of salivary gland lesions which is comparable with Sudarat, Somnuek, Nisarat and Krittika (2012) who found that diagnostic accuracy, sensitivity, specificity 97\%, 81.3\%, 99.1\% indicating good results compared with those previously reported from other institutions (Mihashi et al 2006, Tan et al 2006). Nevertheless, other studies have reported wide variation in sensitivity and specificity of FNA cytology of salivary gland in detecting malignant tumors, ranging from $29 \%$ to $97 \%$ and $84 \%$ to $100 \%$, respectively (Cohen, Patel \& Lin et al 2004).

In the current study the overall sensitivity is $88 \%$, specificity is $98 \%$ and accuracy is 93\% which is higher than Amedee et al 2001 in a review article demonstrated that FNA followed by biopsy has a high overall accuracy of $87 \%$ for malignant mass. Other literatures showed that the overall sensitivity of FNA in diagnosis of malignant mass ranges from $70 \%$ to $100 \%$ (Hirachand et al 2009, Saatian et al 2011) our study results lies within this range.

\section{Conclusion}

We conclude that in general Fine Needle Aspiration Cytology is a highly effective diagnostic procedure in the diagnosis and management of palpable head and neck masses. It is the most accurate when there is a close cooperation between clinician and cytopathologist. But still FNAC is not suitable for the primary diagnosis of lymphoma.

\section{References:}

Afridi S, Malik K, Wahed I. (1995). Role of fine needle aspiration biopsy and cytology in breast lumps. J college of Physicians and Surgeons Pakistan. ; 5:75-7.

Agarwal AK, Sethi A, Sethi D, Malhotra V, Singal S. (2009). Tubercular cervical adenitis: clinicopathologic analysis of 180 cases. J Otolaryngol Head Neck Surg. Oct. 38(5):521-5. [Medline].

Al-Alwan NA, Al-Hashimi AS, Salman MM, Al-Attar EA.(1996). Fine needle aspiration cytology versus histopathology in diagnosing lymph node lesions. East Mediterr Health J;2(2):320-5. 
Al-Mulhim AS, Al-Ghamdi AM, Al-Marzooq HM, Mohammad HA, Gharib IA. (2004). The role of fine needle aspiration cytology and imprint cytology in cervical lymphadenopathy Saudi Med J;25:862-5.

Amedee RG, Dhurandhar NR. (2001). Fine-needle aspiration biopsy. Laryngoscope.;111(9):1551-7. doi: 10.1097/00005537-200109000-00011. [PubMed] [Cross Ref]

Cohen EG, Patel SG, Lin O, Boyle JO, Kraus DH, Singh B, Wong RJ, Shah JP, Shaha AR. (2004). Fine-needle aspiration biopsy of salivary gland lesions in a selected patient population. Arch Otolaryngol Head Neck Surg;130, 773-8.

Das DK. (1999). Value and limitation of fine-needle aspiration cytology in diagnosis and classification of lymphomas: a review. DiagnCytopathol;21:240-9.

Dong HY, Harris NL, Preffer FI, Pitman BP. (2001). Fine needle aspiration biopsy in the diagnosis and classification of primary and recurrent lymphoma: a retrospective analysis of the utility of cytomorphology and flow cytometry. Mod Pathol;14(5):472-81.

Galen, R. S., S. R. Gambino. (1975). Beyond normality-the predictive value and efficiency of medical diagnoses. John Wiley and Sons, New York.1-19 Hehn ST, Grongan TM, Miller TP. (2004).Utility of fine needle aspiration as a diagnostic technique in lymphoma. J Clin Oncol;22(15):3046-52.

Hirachand S, Lakhey M, Akhter J, Thapa B. (2009).Evaluation of fine needle aspiration cytology of lymph nodes in Kathmandu. Medical College, Teaching hospital. Kathmandu Univ Med J;7(26):139-42.[PubMed]

Howlett DC, Harper B, Quante M, Berresford A, Morley M, Grant J. (2007). Diagnostic adequacy and accuracy of fine needle aspiration cytology in neck lump assessment: results from a regional cancer network over a one year period. J LaryngolOtol;121(6):571-9.

Khajuria R, Goswami KC, Singh K, Dudey VK. (2006). Pattern of lymphadenopathy on fine needle aspiration cytology in Jammu.JK Sci;8(3):145-9.

Khan R, Harris SH, Verma AK, Syed A. (2009). Cervical lymphadenopathy: scrofula revisited. J Laryngol Otol. Jul. 123(7):764-7. [Medline].

Keith VE, Harsharan SK, Jerald GZ. (2007).Fine needle aspiration biopsy of lymph nodes in the modern era: reactive lymphadenopathies. Pathol Case Rev;12(1):27-35.

Knappe M, Louw M, Gregor RT. (2000). Ultrasonography-guided fineneedle aspiration for the assessment of cervical metastases. Arch Otolaryngol Head Neck Surg. Sep. 126(9):1091-6. [Medline].

Landgren O, MacDonald AP, Tani E, Ost A, Wedelin C. Aprospective comparison of fine needle aspiration cytology and histopathology in the diagnosis and classification of lymphomas. Hematol J 2004;5:69-76. 
Linda M, Sandhaus MD. (2000). Fine needle aspiration cytology in the diagnosis of lymphoma. Am J Clin Pathol;113:623-7.

Lumley JSP, Chan S, Harris H, Zangana MOM. (1997).Physical signs. 18th edition. Oxford: Butterworth-Heinemann, Oxford. View Review

Maharjan M, Hirachan S, Kafle PK, Bista M, Shrestha S, Toran KC. (2009). Incidence of tuberculosis in enlarged neck nodes, our experience. Kathmandu Univ Med J (KUMJ). Jan- Mar. 7(25):54-8. [Medline].

Mihashi H, Kawahara A, Kage M, Kojiro M, Nakashima T, Umeno H, et al. (2006). Comparison of preoperative fine-needle aspiration cytology diagnosis and histopathological diagnosis of salivary gland tumours. Kurume Med J.;53(1-2):23-27. [PubMed]

Nesreen H. Hafez, Neveen S. Tahoun. (2011). Reliability of (FNAC) in cervical lymphadenopathy. Journal of the Egyptian National Cancer Institute;23,105-114

Rapkiewicz A, Le BT, Simsir A, Cangiarella J, Levine P. (2007). Spectrum of head and neck lesions diagnosed by fine-needle aspiration cytology in the pediatric population. Cancer; 111:242-251.

Russel RCG, William NS, Bulstrode CJK. (2004).Bailey and Love's short practice of surgery. 24th edition. London: Arnold; View Website

Saatian M, Badie BM, Shahriari S, Fattahi F, Rasoolinejad M. (2011). FNA diagnostic value in patients with neck masses in two teaching hospitals in Iran. Acta Med Iran.;49(2):85-8. [PubMed]

Salgarelli AC, Cappare P, Bellini P, Collini M. (2009). Usefulness of fineneedle aspiration in parotid diagnostics. Oral Maxillofac Surg. Dec. 13(4):185-90. [Medline].

Steel BL, Schwartz MR, Ibrahim R. (1995). Fine needle aspiration biopsy in the diagnosis of lymphadenopathy in 1,103 patients. Acta Cytol;39:76-81.

Sudarat Nguansangiam, Somnuek Jesdapatarakul, Nisarat Dhanarak, Krittika Sosrisakorn. (2012). Accuracy of Fine Needle Aspiration Cytology of Salivary Gland Lesions in Thailand. Asian Pacific Journal of Cancer Prevention, Vol 13; 1583-1588

Tan LGL, Khoo MLC. (2006). Accuracy of fine needle aspiration cytology and frozen section histopathology for lesions of the major salivary glands. Ann Acad Med Singapore.;35, 242-8.

Watkinson JC, Wilson JA, Gaze M, Stell PM, Maran AGD. (2000). Stell and Maran's Head and neck surgery, Butterworth-Heinemann, Oxford, 4th edition, chapter 2; p 20-21. View Textbook 